\title{
Pensamento Computacional, Robótica e Educação: um Relato de Experiência e Lições Aprendidas no Ensino Fundamental I
}

\author{
Kênia Luiza Rabelo de Oliveira, Márcia Gonçalves de Oliveira, \\ Mariella Berger Andrade \\ ${ }^{1}$ Instituto Federal do Espírito Santo (Ifes) - Cefor \\ Vitória - Espírito Santo - Brazil
}

\begin{abstract}
Robotics is a knowledge that favors the integration of knowledge from various areas such as science, mathematics, electronics, logic and many others. Thus, in order to develop an interdisciplinary practice, we developed a proposal for children of the 4th grade of Elementary School I so that they could relate the sound waves emitted by the ultrasonic made viable in the LEGO Mindstorms kit to the "echolocalizer", which is used in nature by bats, dolphins and some bird species. The experience resulted in an educational environment rich "surprises" due to the interventions that allowed a new look at the various possibilities made possible by this scenario. For this, the developed research started from a generating question, which led the students to the understanding of theoretical concepts and, later, to the problem solving through programming. We therefore favor greater engagement and autonomy by enabling students to formulate hypotheses relating knowledge of science and mathematics.
\end{abstract}

Resumo. A Robótica é um conhecimento que favorece a integração de conhecimentos de diversas áreas como as ciências, a matemática, a eletrônica, a lógica e várias outras. Dessa forma, com o objetivo de desenvolver uma prática interdisciplinar, desenvolvemos uma proposta para crianças do $4^{\circ}$ ano do Ensino Fundamental I para que pudessem relacionar as ondas sonoras emitidas pelo ultrassônico viabilizado no kit LEGO Mindstorms ao "ecolocalizador", que é utilizado na natureza por morcegos, golfinhos e por algumas espécies de aves. A experiência resultou em um ambiente educacional rico em "encantos" $e$ "surpresas" devido às intervenções que permitiram um novo olhar para as diversas possibilidades viabilizadas por esse cenário. Para isso, a pesquisa desenvolvida partiu de uma pergunta geradora, que levou os alunos à compreensão de conceitos teóricos e, posteriormente, à resolução de problemas por meio de programação. Promovemos, portanto, um maior engajamento e autonomia ao possibilitar que os alunos formulassem hipóteses relacionando conhecimentos de ciências e matemática.

\section{Introdução}

As contribuições pedagógicas da tecnologia nas escolas têm mudado de forma expressiva a maneira como os docentes lidam com a nova era da informação. Embora incorporada nos debates educacionais e nas rotinas escolares, constata-se resistência por parte de docentes que por vezes desconhecem seus recursos, ou enfrentam dificuldade em integrar os conteúdos curriculares às novas tecnologias. 
VIII Congresso Brasileiro de Informática na Educação (CBIE 2019)

Anais do XXV Workshop de Informática na Escola (WIE 2019)

Segundo [Mattar 2010], o currículo tradicional em que a maioria das escolas ainda estão aprisionadas, inclui leituras, escritas e memorizações repetitivas, enquanto o currículo do futuro deveria incluir o conhecimento de softwares, hardwares, eletrônica, programação, games, robótica, nanotecnologia, bem como ética, política e outros conhecimentos que preparam para a vida.

Diante desse cenário, a robótica educacional pode ser um importante recurso tecnológico que possibilita integrar o uso de sucatas ou kits de montagem a conteúdos curriculares, como Ciências da Natureza e Matemática.

A tecnologia e os conteúdos curriculares podem e devem ser indissociáveis, intrínsecos aos debates tecnológicos, considerando seus méritos nos processos de ensino e aprendizagem. Para [Moran 2000], aprender na atualidade exige um movimento motivador que leve o aluno a sair de um estado de passividade. Aprender exige ir além, envolver-se de forma tal que a sensação de inutilidade de conteúdos massivamente obrigatórios em salas de aula sejam capazes de despertar gestos e ações de interação e fazer parte do desejo de aprender.

Com a finalidade de auxiliar docentes do Ensino Fundamental I a reconhecerem possibilidades de integração dos conteúdos curriculares com a Robótica, este projeto propõe a montagem de um Drive Basic do Lego Mindstorms EV3 interligado a um sensor digital ultrassônico, capaz de gerar ondas sonoras e de ler sua frequência, detectando e medindo a distância entre os objetos.

Propomos, portanto, uma iniciação à investigação da vida animal de alguns mamíferos que utilizam "ecolocalizador" para desvio de obstáculos ou de animais predadores. Em relação aos conceitos matemáticos, propusemos conteúdos sobre o comprimento, medidas e distâncias. A estratégia escolhida para medição entre o segmento de reta foi inicialmente o uso das mãos dos alunos. Em seguida, após debates e experiências quanto à precisão das medidas, a régua e a fita métrica foram citadas nas discussões.

\section{Revisão de Literatura}

Em conformidade com a necessidade de uma mudança do ensino para uma abordagem mais centrada no aluno, [Papert 1994] sugere evitar ações pedagógicas que moldem a mente e recomenda ações em que os padrões de desenvolvimento do aprendiz progridam.

Considerando a importância da robótica em práticas pedagógicas para desenvolvimento de habilidades, destacamos os trabalhos de [Campos 2017] e [Neto et al. 2018].

Em uma abordagem mais educacional, [Campos 2017] faz uma investigação atual da robótica na educação e no Brasil, destacando o cenário e as práticas em campo. $\mathrm{O}$ também artigo apresenta uma investigação do estado da arte da robótica na educação, uma leitura das teorias de aprendizagem e por fim viabiliza contribuições.

Já [Neto et al. 2018] destaca a importância da robótica cada vez mais presente nas práticas pedagógicas e o quanto a ferramenta apresenta características de dinamismo ao processo de ensino e de aprendizagem. Dessa forma, a pesquisa se aproxima das reflexões que destacam o uso de robôs e os alunos como construtores de conhecimentos em atividades que levam ao raciocínio lógico e matemático. 
VIII Congresso Brasileiro de Informática na Educação (CBIE 2019)

Anais do XXV Workshop de Informática na Escola (WIE 2019)

\section{Planejamento da Experiência}

Inicialmente foi desenvolvido um projeto educacional com a Utilização da Robótica como ferramenta pedagógica com os recursos apresentados na Figura 1. A Tabela 1 apresenta $o$ planejamento dessa experiência interdisciplinar.

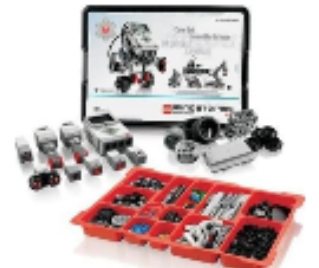

(a)

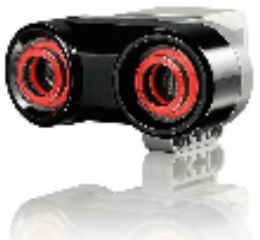

(b)

Figura 1. (a) Kit Lego Mindstorms; (b) Sensor Ultrassônico

Tabela 1: Planejamento de Experiência de Robótica

Nome do projeto: Os robôs, a vida animal e a matemática em minha sala de aula.

Série/ciclo envolvido: $4^{\circ}$ Ano Fundamental I Disciplinas envolvidas: Matemática, Ciências e Tecnologia (robótica)

Acessórios utilizados: internet, smartphones, mesa de suporte e filmagens

Objetivo Geral: Promover a interdisciplinaridade entre as disciplinas Ciências e Matemática, por intermédio da robótica a partir do uso digital de um Sensor Ultrassônico capaz de medir distância.

Objetivos Específicos: Promover um ambiente que gere cooperação e curiosidade; produzir a montagem de protótipo com o uso do sensor ultrassônico; introduzir conceitos de programação; incentivar o raciocínio lógico e a sofisticação do pensamento; enfatizar a investigação científica; demonstrar conceitos da matemática acerca de distância em centímetros; demonstrar conceitos de ciências acerca da vida animal desses mamíferos e suas curiosidades; apontar e relacionar os conhecimentos das disciplinas de ciências e matemática no projeto executado no laboratório de Robótica.

Avaliação: as avaliações se deram pela observação, diálogo, interação, cooperação, interação, pesquisas direcionadas a cada conteúdo e habilidade de analisar criticamente e colaborativamente todo o processo ao longo do projeto. 
VIII Congresso Brasileiro de Informática na Educação (CBIE 2019)

Anais do XXV Workshop de Informática na Escola (WIE 2019)

\section{Relato da Experiência}

Para a atividade proposta consideramos uma turma de dez alunos do quarto ano do Ensino Fundamental I, com idades entre 10 e 11 anos, de uma escola pública da rede Municipal de Vila Velha do Estado do Espírito Santo.

O diálogo iniciou-se com uma pergunta que problematizou as discussões no que se refere a medidas, distâncias e como seria possível a determinação exata do intervalo entre dois postos pré marcados na mesa de trabalho.

As indagações de que modo seria possível a exatidão entre as distâncias foi rapidamente solucionada com o uso das mãos, como um possível instrumento de medição. No entanto, as tentativas os levaram às interrogações: "Como vamos ter certeza da distância entre os dois pontos se nossas mãos têm tamanhos diferentes?".

Conforme [Moran 2000], esse cenário envolveu de forma mais plena o professor em sua função docente como conhecedor de tecnologias às quais ajusta-se para interpretar e usá-las em favor de um processo de ensino e de aprendizagem com mediação pedagógica significativa. As sugestões de qual instrumento de medição poderia nos auxiliar foram prontamente sugeridas e a régua flexível aquietou os ânimos como solução para os primeiros questionamentos. Posteriormente, os alunos se interessaram em realizar várias outras formas de medições tais como: o tamanho em centímetros de cada mão, altura dos colegas, altura da professora e largura da mesa de trabalho, conforme Figura 2.

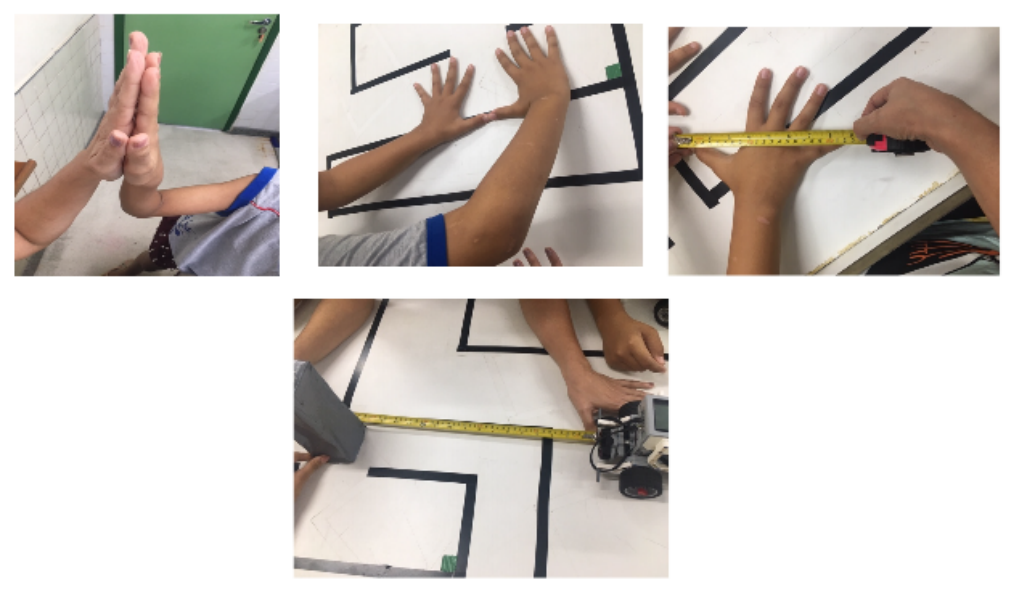

Figura 2. Trabalhando grandezas e medidas nas aulas de robótica

Em conformidade com [Gadanidis et al. 2016], é importante explorar não somente as tecnologias, mas intensificar suas potencialidades em uma perspectiva pedagógica, explorando assim a noção de design experimental, isto é, de um ambiente de investigação, formulando suposições, inferências e estimativas que busquem soluções para problemas matemáticos.

Finalmente, os alunos foram indagados se existiria algum animal que tivesse algum tipo de sensor que o auxiliasse a não sofrer com colisões, como o sensor ultrassônico que justamente era capaz de desviar-se de obstáculos. A resposta foi imediata: "Os golfinhos professora, eles emitem um som que ajuda lá no fundo do mar!". Trilhamos então 
VIII Congresso Brasileiro de Informática na Educação (CBIE 2019)

Anais do XXV Workshop de Informática na Escola (WIE 2019)

uma busca na internet para saber mais sobre animais que utilizam "ecolocalizadores", como os golfinhos, os morcegos e algumas espécies de aves.

Em seguida, iniciamos a análise da programação, de seus recursos e de conceitos. Sistematizamos então os conceitos sobre motores, limitação de velocidade, potência e força, comparações de menor ou igual, distância máxima entre obstáculo e sensor, rotação em graus e, por fim, ciclo de repetição.

\section{Conclusão}

Este trabalho apontou algumas possibilidades de intervenção interdisciplinar entre a Robótica Educacional e conteúdos de Ciências e Matemática em uma escola pública do município de Vila Velha ES.

A relevância de atividades associadas ao uso de robôs possibilita um ambiente repleto de descobertas que envolvem desde a construção da Drive Basic, quanto a formação crítica e social dos discentes que, na tentativa de solucionar problemas do dia a dia, ampliam seu desenvolvimento psicomotor e cognitivo.

Os principais reflexos da prática da atividade em uma turma de $4^{\circ}$ ano do Ensino Fundamental I indicaram como podemos promover um ambiente atraente para a experimentação, resolução de problemas e compreensão de conteúdos em uma abordagem interdisciplinar.

Portanto, espera-se que as intervenções expostas nesse trabalho contribuam para um repensar de nossas práticas pedagógicas, que precisam estar incorporadas não somente aos avanços tecnológicos mas também a finalidades educacionais.

Conforme [Freire 2014], um aluno curioso pode abalar algumas certezas em nós professores, mas de outro lado, essa mesma curiosidade em que é permitido ao aluno a liberdade de questionar, permite colocar o professor como mediador de um trabalho onde se compartilha ideias em um ambiente colaborativo e enriquecedor. Dessa forma, a tecnologia educacional deve ser utilizada de forma crítica e favorecer o desenvolvimento de habilidades e o trabalho colaborativo em atividades interdisciplinares

\section{Referências}

Campos, F. R. (2017). Robótica educacional no brasil: questões em aberto, desafios e perspectivas futuras. Revista Ibero-Americana de Estudos em Educação, 12(4):21082121.

Freire, P. (2014). Por uma pedagogia da pergunta. Editora Paz e Terra.

Gadanidis, G., de Carvalho Borba, M., and da Silva, R. S. R. (2016). Fases das Tecnologias Digitais em Educação Matemática: sala de aula e internet em movimento. Autêntica.

Mattar, J. (2010). Games em educação. Pearson Educación.

Moran, J. M. (2000). Novas tecnologias e mediação pedagógica. Papirus Editora.

Neto, M., dos Santos, C. A. M., de Souza, E. E., and Fonseca, M. G. (2018). Robótica educacional uma ferramenta para ensino de lógica de programação no ensino fundamental. In Anais do Workshop de Informática na Escola, volume 24, page 315.

Papert, S. (1994). A máquina das crianças. Porto Alegre: Artmed. 